\title{
Problem-Based Learning \& Task-Based Learning Curriculum Revision Experience of a Turkish Medical Faculty
}

\author{
Berna Musal* $^{*}$ \\ Department of Medical Education, Dokuz Eylul University, Faculty of Medicine, Izmir, Turkey \\ Email: berna.musal@deu.edu.tr
}

Received October $29^{\text {th }}, 2013$; revised November $29^{\text {th }}, 2013$; accepted December $7^{\text {th }}, 2013$

\begin{abstract}
Copyright $(\underset{0}{ } 2013$ Berna Musal. This is an open access article distributed under the Creative Commons Attribution License, which permits unrestricted use, distribution, and reproduction in any medium, provided the original work is properly cited. In accordance of the Creative Commons Attribution License all Copyrights (C) 2013 are reserved for SCIRP and the owner of the intellectual property Berna Musal. All Copyright $\mathbb{C} 2013$ are guarded by law and by SCIRP as a guardian.
\end{abstract}

The aim of this paper is to introduce the basic principles of Dokuz Eylul University Faculty of Medicine's educational program and curriculum revision studies carried out within the last three years.

Keywords: Medical Education; Problem-Based Learning; Task-Based Learning; Curriculum Revision

\section{Introduction}

The first part of the article, which aims to introduce the basic principles of Dokuz Eylul University Faculty of Medicine's (DEUFM) educational program and the curriculum revision studies carried out within the last three years, offers summarized information on the educational program model, general principles and the methods used. The second part includes information on the curriculum revision studies carried out with the outcome-based approach since 2009 and the basic principles and block structures of the new curriculum.

\section{Basic Principles of the Educational Program}

DEUFM applies the Problem Based Learning (PBL) program which has been applied in Turkey for the first time since the academic year of 1997-1998 in the first three years of the educational program; and Task Based Learning (TBL) as of the academic year of 2000-2001 in the fourth and fifth years. The sixth year is maintained as the internship period. DEUFM's aim is defined as training the physicians who are equipped with basic professional knowledge and skills, capable of seeing the human as a whole with their biological, psychological and social aspects, capable of communicating with their surroundings, sensitive towards the health problems of the community and capable of producing solutions, willing to learn during their professional life and capable of improving themselves (Musal et al., 2002). In configuring the educational program, six educational strategies (student-centered, problem based, integrated, community based, involving electives and systematic) which are representatives of innovative approaches of SPICES model described by Harden were adopted in 1997 (Harden et al., 1984).

PBL is the principal educational strategy in the first three years of the undergraduate program. The curriculum covers

* On behalf of all faculty members contributing to the educational management and curriculum study groups of Dokuz Eylul University Faculty of Medicine's educational program. primary health problems of the community. The scenarios which are used in the PBL sessions are built to involve not only biological objectives but also societal and behavioral objectives. Through the field studies, it is aimed to have students go out of the borders of the university hospital; and gain sensitivity about the health problems of the community and social factors influencing health and health policies of the country. Students learn new things, concepts, use their knowledge, notice where to use them and better understand, and improve their analysis, synthesis and problem solving skills in PBL sessions. Lectures, usually limited to one hour per day, provide some clues to increase students' motivation and curiosity and support the students during the periods of independent learning. Basic clinical and procedural skills are acquired in clinical skills laboratories and basic science practices are implemented in laboratories. There are special study modules in the first three years' program, elective programs in the clinical years so that students can gain deep knowledge and skills in the subjects of their interest. Due to the nature of the PBL program; knowledge and skills are repeated and connected in the related blocks among years and tasks in higher levels through the existing interdisciplinary integration as well as a spiral configuration. Approximately $20 \%-30 \%$ of the educational program is allocated to the independent learning process (Musal et al., 2002).

The TBL method for the $4^{\text {th }}$ and $5^{\text {th }}$ years of the educational program as the continuation of PBL in clinics was adopted in the 2000-2001 academic year. TBL is an educational strategy primarily defined by Harden which combines PBL and integrated system with multidisciplinary learning and training perspective and offers the student rich learning opportunities of different disciplines. The tasks which deal with a symptom or a clinic problem of a patient, provide a focus for learning in TBL. However, the aim of learning is not limited only to objectives such as getting task oriented histories, making physical examination, referring diagnosis and treatment, but also includes acquiring general professional skills. (Harden et al., 1996; Harden et al., 2000; Race, 2000; Virjo et al., 2001). The objec- 
tives of DEUFM $4^{\text {th }}$ and $5^{\text {th }}$ year program are defined as getting task oriented histories, making physical examinations, referring differential diagnosis and treatment, being able to make task related procedures, gaining knowledge and skills in the social dimension of the diseases and preventive medicine. The objectives for general skills, on the other hand, include the ability to integrate basic and clinical sciences with each other, critical thinking, problem solving, gaining communication skills, learning ethic and legal responsibilities. The tasks include the basic clinical problems with which students encounter in their profession. The selected tasks enable students to gain knowledge and skills in relation to their clinical problems, and integrate with basic medical sciences. Attention is paid to the selection of the clinical problems in relation to more than one department in order to transfer learning facilities and experiences of different disciplines and to gain multidisciplinary approach. Interdisciplinary practices, lectures and patient visits are organized in each task's schedule.

There are total 38 tasks in each eight-week "Internal Medical Sciences", "Gastrointestinal system-Masses", "Paediatrics" and "Surgical Medical Sciences" blocks within $4^{\text {th }}$ year program. There are total 36 tasks in each eight-week "Emergency Medicine", "Nervous System-Mental Health and Mental Disorders", "Skin and Joints-Locomotor system", "Eye-Ear Nose and Throat" and "Obstetrics and Gynecology" blocks in $5^{\text {th }}$ year program. At the beginning of $4^{\text {th }}$ year program, students attend rational drug use, evidence-based medicine and infection control courses. Elective internship period is determined as two weeks in the $4^{\text {th }}$ year, one month in the $5^{\text {th }}$ year (Ozkan et al., 2004; Ozkan et al., 2006).

Internship program is predominantly applied as the use, improvement of knowledge and skills learned in the previous years and preparation process for becoming a physician. The educational objectives of $6^{\text {th }}$ year program were reviewed again in line with the national core curriculum and constantly updated DEUFM curriculum objectives. In the process of reviewing the objectives, some changes were made in the structure of twomonth Internal Medicine, Obstetrics and Gynecology, Paediatrics, Emergency Medicine-General Surgery, Public Health and one-month Psychiatry and Elective blocks (Ergor et al., 2009). Starting with the academic year of 2009-2010, one-week duration "Cardiology", "Chest Diseases", "Neurology" and" Ear Nose and Throat" blocks were added within the $6^{\text {th }}$ year program. It was intended to configure those blocks to include the primary health problems to be encountered by the physician in the primary health care units and predominantly maintain it through policlinic studies. Internship program is constantly evaluated and revised through the regular monthly meetings of the intern representatives and faculty members who are in charge of internship and program evaluation studies.

\section{Educational Program Revision Studies}

In DEUFM, all components of the educational program, verbal and written feedback and the qualitative, quantitative studies which are implemented within the scope of the program evaluation project are constantly evaluated and necessary changes are made (Musal et al., 2008). After a 12 years of experience in PBL curriculum, in 2009 we decided to make an extensive revision in the program for thorough review and update of the program objectives and to reanalyze what we expected from the graduates. It was intended to have no changes in the basic principles of the educational program, have it student-centered, focus on active learning methods such as PBL and TBL, and community oriented, allow community based practices, have skill training based on competency, offer the students opportunities to gain deep knowledge and skills in their area of interests (Musal et al., 2010).

Competencies expected from the students at graduation phase are defined as follows:

- Understand basic and clinical sciences and assess the scientific foundations of medical knowledge in critical terms,

- Address patients and diseases with their biopsychosocial dimensions and understand the effects of ecosystems on human health,

- Apply basic principles for the protection of individual and community health,

- Have knowledge and skills to diagnose, treat and monitor diseases,

- Have the skills of self-learning and self-assessment,

- Have effective communication with patients and their relatives, colleagues and other healthcare workers and take the lead,

- Effective utilization of information technologies in physician's practices,

- Perform physician's practices in compliance with professional values and ethic principles,

- Assess the effects of health systems, policies and practices on individual and community health.

Blocks, stages and themes which will exist in the general structure of the educational program were determined as a result of the presentations and discussions made in the Undergraduate Level Education Board. The educational program was planned to be dealt with in four stages. Stage 1 which includes normal structure and functioning covers the whole $1^{\text {st }}$ year and the first half of $2^{\text {nd }}$ year; Stage 2 which includes pathological processes covers the second half of the $2^{\text {nd }}$ year and the whole $3^{\text {rd }}$ year; Stage 3 covers clinical clerkship and Stage 4 covers internship period. The list of the blocks which is available in the six-year educational program is given in Appendix 1.

In the curriculum revision study, it was decided to use the outcome-based approach (Harden et al., 1999; Harden, 2007) which stipulates the clear definition of what is expected from the graduate and planning the educational program by considering the competencies to be demonstrated by the student at the end of the education. Block and theme study groups were created taking the representations of the relevant field specialists into account.

The names of the block study groups are presented below:

- Introduction to medical sciences 1

- Introduction to medical sciences 2

- Reproduction, urogenital, endocrine

- Information management-research 1 and 2

- Gastrointestinal system, nutrition, metabolism

- Respiration, circulation, blood

- Neural sciences

- Locomotor system and skin

- Blood, infection, immunity

- Multisystem

- Life Cycle

- Introduction to clinical sciences

The names of the theme study groups are presented below:

- Community Health and Preventive Medicine,

- Human Behaviors and Their Foundations, 
- Ethics and Law,

- Professional Skills and Values.

In line with the study plan and calendar which were prepared by the Deanship and the Department of Medical Education (DME), the groups created the lists of diseases, conditions/problems, symptoms to be frequently encountered/important/life threatening in relation to the block/theme. The lists which were created by the study groups in which 193 faculty members from 41 Departments took office were later sent to all Departments and the review of the list and the determination of the competence levels (information, diagnosis, diagnosis-treatment management, emergency attempt, preventive medicine) expected from the graduate in relation to the defined diseases, conditions/problems, symptoms were requested. The opinions of the primary health care physicians were taken in the same time period. The study groups considered the opinions coming from the Departments and primary health care physicians, and determined the six-year objectives of the blocks and themes and then objective levels in compliance with the lists and competence levels. Information and counseling support was provided by DME at all phases. The determined objectives were compared to the national core curriculum, previous curriculum objectives and international references. Following the completion of the distribution of the objectives defined by all block study groups to different stages, "Community Health and Preventive Medicine", "Human Behaviors and their Foundations", "Ethics and Law", "Professional Skills and Values" study groups implemented the distribution of the objects which were simultaneously determined with block study groups to the blocks at different phases. Following the three-month intensive effort of the study groups, the block boards which consisted of the faculty members commissioned by the Deanship from the Departments associated with the objectives of the blocks started to prepare block programs and educational materials based on the defined objectives.

The new educational program includes system blocks which repeat in different stages as well as Introduction 1 block for the purpose of preparation for normal structure and functioning, Introduction 2 blocks for the purpose of preparation to pathological processes. In Information Management Research I and II blocks, basic principles of the scientific principles, research types, research ethics, biostatistics concepts and tests, information management in healthcare, article and report preparation objectives are handled and the information and skills obtained in these blocks are applied through special study modules. In the Multisystem block which exists at the end of the first three years, it is aimed to use and synthesize the key biological information obtained in the first three years through themes such as shock, sepsis, metastatic cancer, autoimmune disease and polytrauma. In the Life Cycle block, on the other hand, it is aimed to address the health problems that may be encountered in all periods of human life from birth to death predominantly with their social, behavioral, ethic and forensic medicine dimensions for the reinforcement and development of the knowledge and skills obtained by the students in the first three years in health risks, health protection and improvement. The threeweek Introduction to Clinical Sciences block which exists at the beginning of the $4^{\text {th }}$ year program, on the other hand, was intended to include diagnostic medicine objectives in addition to rational drug use, infection control, evidence-based medicine items which were available in the previous years. The existing block structures in the $4^{\text {th }}$ and the $5^{\text {th }}$ year program were up- dated in compliance with the objectives defined in the new curriculum study.

\section{Conclusion}

Integration has been described as an important educational strategy in medical education (Harden, 2000). A great effort had been made to achieve integration throughout the new curriculum at all levels in DEUSM. The vertical and horizontal integration levels of the new curriculum were reviewed and necessary arrangements were made through the meetings which were held once a week for one year in the academic year of 2010-2011 by the Curriculum Integration Board which was created by taking the representations of the study groups and Departments into account. The block programs are revised in line with the block board reports and student feedbacks in the periodical meetings which are still made by the Curriculum Board.

The new educational program is applied in all years' program commencing from the $1^{\text {st }}$ year program in phases as of the academic year of 2009-2010. All components of new educational program are evaluated and revised within the concept of program evaluation studies which include qualitative, quantitative studies, and block reports.

\section{REFERENCES}

Ergor, A., Taskiran, C., Musal, B., Akalin, E., \& Unsal, E. (2009). Dokuz Eylul University Medical Faculty $6^{\text {th }}$ Year Education Program Improvement Works, Accreditation in Medical Education and Program Assessment Symposium Book. Medical Education Development Association, Pamukkale University Medical Faculty, 4-5 June 2009.

Harden, R. M., Sowden, S., \& Dunn, W. R. (1984). Educational strategies in curriculum development: The SPICES model. Medical Education, 18, 284-297. http://dx.doi.org/10.1111/j.1365-2923.1984.tb01024.x

Harden, R. M., Laidlaw, J. M., Ker, J. S., \& Mitchell, H. E. (1996). Taskbased learning: An educational strategy for undergraduate, postgraduate and continuing medical education. AMEE Medical Education Guide No: 7, Medical Teacher.

Harden, R. M., Crosby, J. R., \& Davis, M. H. (1999). Outcome-based education: Part 1, An introduction to outcome-based education. AMEE Guide No.14. Medical Teacher, 21, 7-14. http://dx.doi.org/10.1080/01421599979969

Harden, R. M., Crosby, L., Davis, M. H., Howie, P. W., \& Struthers, A. D. (2000). Task-based Learning: The answer to integration and problem-based learning in clinical years. Medical Education, 34, 391-397. http://dx.doi.org/10.1046/j.1365-2923.2000.00698.x

Harden, R. M. (2000). The integration ladder: A tool for curriculum planning and evaluation. Medical Education, 34, 551-557. http://dx.doi.org/10.1046/j.1365-2923.2000.00697.x

Harden, R. M. (2007). Learning outcomes as a tool to assess progression. Medical Teacher, 29, 678-682. http://dx.doi.org/10.1080/01421590701729955

Musal, B., Akalın, E., Kılıç, O., Esen, A., \& Alıcı, E. (2002). Dokuz Eylul University Medical Faculty Problem-Based Learning Program, Processes and the Role of Tutors. Turkish Medical Education World, 9, 39-49.

Musal, B., Taskıran, C., Gursel, Y., Ozan, S., Tımbıl, S., \& Velipasaoğlu, S. (2008). An example of program evaluation project in undergraduate medical education. Education for Health, 21. http://www.educationfor health. net/

Musal, B., Taskiran, C., Timbil, S., Velipasaoglu, S., Gursel, Y., Ozan, S., Atabey, N., Akalin, N., \& Abacioglu, H. (2010). Curriculum Revision Studies in Dokuz Eylul University Medical Faculty. VI. National Medicine Congress Summary Book, Medical Education De- 
velopment Association, Adnan Menderes University Medical Faculty, 2-5 June 2010.

Ozkan, H., Degirmenci, B., Musal, B., Itil, O., Akpınar, H., Akalın, E., Ozkan, S., \& Alıcı, E. (2004). Task-based learning in Dokuz Eylul University Medical School, Turkey. Medical Teacher, 26, 279-280.

Ozkan, H., Degirmenci, B., Musal, B., Itil, O., Akalın, E., Kılınç, O., Ozkan, S., \& Alıc1, E. (2006). Task-based learning program for clini- cal years of medical education. Education for Health, 19, 32-42. http://dx.doi.org/10.1080/13576280500534826

Race, P. (2000). Task-based learning. Medical Education, 34, 335-336. http://dx.doi.org/10.1046/j.1365-2923.2000.0706a.x

Virjo, I., Martilla, D. H., \& Mattila, K. (2001). Task-based learning in undergraduate medical education. Medical Teacher, 23, 55-58. http://dx.doi.org/10.1080/0142159002005604

\section{Appendix. Blocks That Exist in the Educational Program}

\section{$1^{\text {st }}$ Year}

STAGE 1

- Introduction to medical sciences I-8 weeks

- Reproduction, urogenital, endocrine- 8 weeks

- Information management-research-1 week

- Gastrointestinal system, metabolism, nutrition-8 weeks

- Respiration, circulation, blood-9 weeks

$2^{\text {nd }}$ Year

- Neural sciences-8 weeks

- Information management- research-1 week

- Locomotor system, dermatology-8 weeks

- Introduction to medical sciences-6 weeks

STAGE 2

- Blood, infection, immunology-6 weeks

- Gastrointestinal system, metabolism, nutrition-6 weeks

$3^{\text {th }}$ Year

- Reproduction, urogenital, endocrine-6 weeks

- Neural sciences-6 weeks

- Locomotor system, dermatology -6 weeks

- Respiration Circulation-6 weeks

- Multisystem -6 weeks

- Life cycle-6 weeks

$4^{\text {th }}$ Year

- Introduction to clinic-3 weeks
- Paediatrics-8 weeks

- Internal medicine-8 weeks

- Gastrointestinal system-masses-8 weeks

- Respiration Circulation-8 weeks

- Elective-2 weeks

$5^{\text {th }}$ Year

- Emergency medicine- 8 weeks

- Obstetrics and gynecology -8 weeks

- Nervous system-Mental health-8 weeks

- Locomotor system- dermatology-8 weeks

- Ear nose and throat, Eye-4 weeks

- Elective-4 weeks

$6^{\text {th }}$ Year

- Internal medicine-6 weeks

- Chest Diseases-1 week

- Cardiology-1 week

- Obstetrics and gynecology-8 weeks

- Public health-8 weeks

- Emergency medicine-6 weeks

- Surgery-2 weeks

- Psychiatry-4 weeks

- Neurology-1 week

- Ear nose and throat-1 week

- Elective-2 weeks 